Dept. of Surgery and Gynaecology,

Faculty of Vet. Medicine, University of Gezira,

Tamboul, P.O Box 20.

\title{
FERTILITY RESPONSE OF NUBIAN GOATS AFTER OESTRUS SYNCHRONIZATION WITH PROGESTERONE, PGF2A AND ECG
}

(With One Table)

\author{
By \\ E.A. BABIKER; SH-E.A. MAKAWI* \\ and SUMIA H. HUSSEIN**
}

* Dept. of Obstetrics and Gynaecology, Faculty of Vet. Medicine,

University of Khartoum, Khartoum North, P.O Box 32.

** National A.I. Centre, P.O. Box 50, Khartoum North, Sudan.

(Received at 25/2/2010)

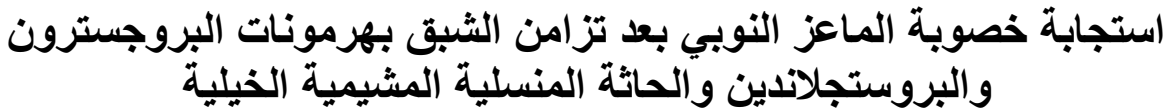

السر عبد الحي بابكر ، شرف الدبن عبد الله مكاوي ، سمية حسن حسين

أجريت هذه الدر اسة لمعرفة فاعلية المعاملات الهرمونية في تحفيز وتز امن الثبق وزيادة

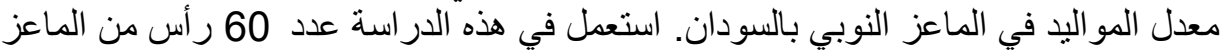

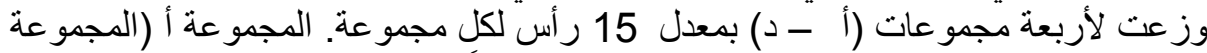

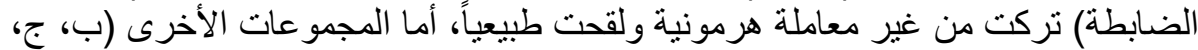

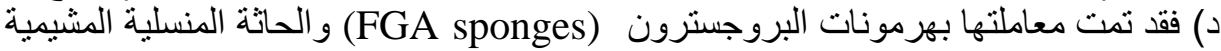

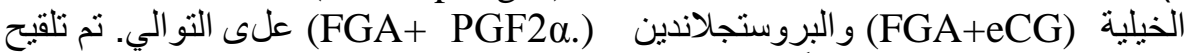

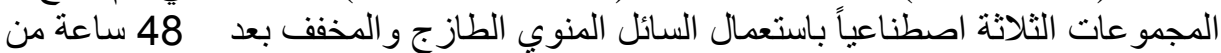

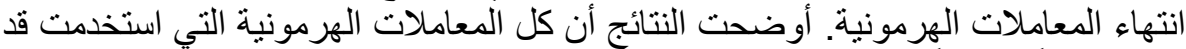

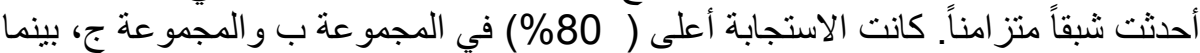

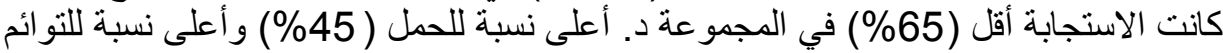

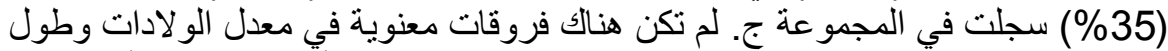

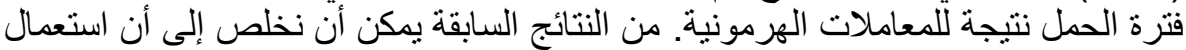

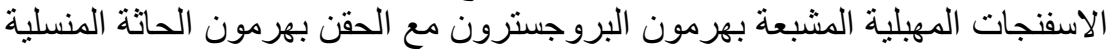

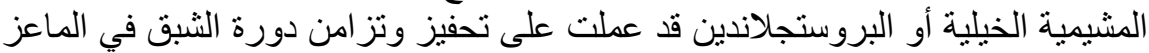
النوبي. 
The reproductive performance following oestrus synchronization and artificial insemination (AI) was evaluated during autumn and early winter in 60 Nubian goats in the Sudan to determine the best hormonal approach in inducing and synchronizing oestrus. The animals were divided into 4 groups (A-D). All goats, except the control group, were synchronized for 12 days with flourogestone acetate (FGA) sponges followed by an IM injection of equine chorionic gonadotropin (eCG) or cloprostenol (PGF2 $\alpha$ ) at progestagen withdrawal. Cervical artificial inseminations (AI) were performed at $48 \mathrm{~h}$ after FGA withdrawal using fresh diluted semen. Results obtained indicated that all hormonal treatments used were efficient to induce and synchronize oestrus in Nubian goats. However, the response in treatment B and treatment $\mathrm{C}$ (FGA and FGA/eCG) were higher (80\%) than FGA/PGF2 $\alpha$ treatment $(65 \%)$. Animals treated with FGA/eCG recorded higher pregnancy rate $(45 \%)$ and kidding rate $(35 \%)$. The fertility as indicated by pregnancy and kidding rates was lower in animals treated with FGA/PGF2 $\alpha$ and in the control group. In the present study, kidding rate, fecundity, twining rate and gestation length were not significantly affected by synchronization methods. Therefore, the use of progestagen sponges with or without eCG or PGF2 $\alpha$ was effective in induction and synchronization of oestrus in Nubian goats.

Keywords: Oestrous synchronization, Nubian goats, FGA, eCG, PGF2 $\alpha$.

\section{INTRODUCTION}

Oestrus detection is time consuming and subject to human error. Therefore, synchronization of oestrus and ovulation in a group of females allows one to predict the time of oestrus with reasonable accuracy and minimizes the time and difficulty involved in detecting oestrus (Abu et al., 2008). Oestrous synchronization together with AI in goats is important in the improvement of reproductive efficiencies and management programmes. Successful techniques must not only establish tight synchrony, but also provide an acceptable level of fertility upon AI or natural mating (Wildeus, 2000; Lassala et al., 2004; Chao et al., 2008). Methods of synchronization have included techniques as simple as alteration of light patterns or manipulation of social inputs (i.e. the buck effect) and as complex as varying timed hormonal treatments (Whitely and Jackson, 2004). This can be achieved in farm animals when the luteal phase is shortened by premature luteolysis of functional 
corpora lutea or the phase is extended by suppressing follicular growth (Abu et al., 2008).

A number of workers have administered progestagens in cyclic female goats with satisfactory results (Wildeus, 2000; Dogan et al., 2005; Abu et al., 2008). At the same time, prostaglandin F2 $\alpha$ and its synthetic analogues have been found to be more efficiently used to synchronize oestrus in goats during natural breeding season and was found to be the more convenient and economical method (Muna et al., 1998; Wildeus, 2000; Faruk et al., 2004; Bitaraf et al., 2007). PGF2 $\alpha$ application together with FGA increased oestrus response rates (Dogan et al., 2005). The use of Gonadotropins such as eCG in conjunction with intravaginal progestagen treatment, regardless of PGF $2 \alpha$ administration was found to be efficient method for oestrus induction and synchronization in sheep and goats (Fonseca et al., 2005; Dogan and Nur, 2006; Mehmet and Mehmet, 2006).

Although oestrus synchronization in goats has been accomplished using several protocols with varying degrees of success, very scarce work has been conducted concerning the efficacy of oestrus synchronization in Sudanese goats. Therefore, the objective of the present study was to compare the efficiency of FGA sponges in combination with either eCG or cloprostenol in inducing and synchronizing oestrus cycle in Nubian goats in the Sudan and compare the fertility rates obtained following AI.

The objective of the present study was to compare the efficiency of different hormonal treatments in synchronizing oestrus in Nubian goats and compares the fertility rates obtained following $\mathrm{AI}$ at the induced oestrus.

\section{MATERIALS and METHODS}

\section{Location:}

This study was carried out at the National Artificial Insemination Centre, Khartoum North, Sudan. The area is located at a latitude of $15^{0} 36^{\prime} \mathrm{N}$, a longitude of $32^{0} 33^{\prime} \mathrm{E}$ and an altitude of $380 \mathrm{~m}$ above sea level.

\section{Experimental animals:}

The experiment was performed on a total of 60 mature Nubian dairy does. The does were $2-5$ years of age with an average body weight of $30 \mathrm{~kg}$. The animals were kept on suspended pens and fed daily with a ration that contained wheat bran (43\%), molasses (32\%), ground nut 
cake (20\%), urea (3\%) and salt (2\%). Alfalfa hay was fed ad libitum. Water and mineral licks were always available. Before the beginning of the experiment, all does were checked for the absence of pregnancy by radioimmunoassay (RIA).

\section{Treatments:}

The animals were allocated to four groups each of 15 does. The four treatment groups consisted of the following:

Treatment A (control): Does received no treatment and were naturally mated at natural heat. All other groups received intravaginal progesterone-impregnated sponges (40 $\mathrm{mg}$ of flourogestone acetate, FGA, Sanofi, France) for 12 days.

Treatment B: Does were artificially inseminated $48 \mathrm{~h}$ after sponge removal.

Treatment C: Does were injected with 300 - 500 IU of PMSG (Intervet, UK) intramuscularly at time of sponge removal and artificially inseminated $48 \mathrm{~h}$ later.

Treatment D: Does were injected with PGF2 $\alpha$ (cloprostenol, Coopers, France) at time of sponge removal and artificially inseminated $48 \mathrm{~h}$ later.

All does were monitored for oestrus behaviour after each treatment. The oestrus signs observed were: restlessness, constant wagging of the tail from side to side, vaginal mucous and mounting activities. Cervical artificial inseminations (AI) were performed using fresh extended (Tris extender) Saanen semen. A volume of $0.5 \mathrm{ml}$ fresh extended semen containing $200 \times 10^{6}$ sperms was administered intracervically. Conception rates based on non-return were determined 21 - 60 days following insemination. Early pregnancy was confirmed by RIA for measuring progesterone (P4) in serum. Samples were collected in heparinized tubes at weakly intervals and centrifuged for $15 \mathrm{~min}$. The plasma was stored at - 20 until assayed for progesterone. RIA kits were supplied by the International Atomic Energy Agency.

\section{Statistical Analysis:}

Numbers of does showing oestrus, pregnancy and kidding were analyzed using Chi-square $(\chi 2)$ technique, and other data were analyzed by the analysis of variance using Statistical Package for Social Science.

\section{RESULTS}

The results in terms of oestrus response, pregnancy rate, kidding rate, fecundity (number of kids born/number of females kidded), twining rate and gestation length are set out in Table (1). The results revealed 
that the degree of oestrus response due to hormonal treatments was not significantly different $(\mathrm{p}>0.05)$; although oestrus response obtained from FGA/PGF2 $\alpha$ (Treatment D) was the lowest (65\%). Conception rate showed significant treatment effect. It was highest (40 and 45\%) in FGA and FGA/PMSG groups, respectively (Treatments B and C) and least (30\%) in FGA/PGF2 $\alpha$ treatment and the control group (20\%). Fertility measured by the kidding rate was not significantly different between groups, although it was better (35\%) in treatment $\mathrm{C}$ and low (20\%) in the control group. Twining rate, fecundity and gestation length were not significantly affected by synchronization methods.

Table 1: Fertility of Nubian goats after different oestrus synchronization treatments.

\begin{tabular}{|l|c|c|c|c|}
\hline \multirow{2}{*}{\multicolumn{1}{|c|}{ Parameter }} & \multicolumn{4}{c|}{ Treatments } \\
\cline { 2 - 5 } & $\mathrm{A}$ & $\mathrm{B}$ & $\mathrm{C}$ & $\mathrm{D}$ \\
\hline $\begin{array}{l}\text { No. of animals No. of } \\
\text { animals }\end{array}$ & 15 & 15 & 15 & 15 \\
\hline Oestrus response (\%) & $100^{\mathrm{a}}$ & $80^{\mathrm{b}}$ & $80^{\mathrm{b}}$ & $65^{\mathrm{b}}$ \\
\hline Conception rate (\%) & $20^{\mathrm{b}}$ & $40^{\mathrm{a}}$ & $45^{\mathrm{a}}$ & $30^{\mathrm{b}}$ \\
\hline Kidding rate (\%) & $20^{\mathrm{a}}$ & $30^{\mathrm{a}}$ & $35^{\mathrm{a}}$ & $25^{\mathrm{a}}$ \\
\hline Fecundity & $0.25 \pm 0.05^{\mathrm{a}}$ & $0.65 \pm 0.5^{\mathrm{a}}$ & $0.75 \pm 0.5^{\mathrm{a}}$ & $0.45 \pm 0.5^{\mathrm{a}}$ \\
\hline Twining rate & $0.16^{\mathrm{a}}$ & $0.37^{\mathrm{a}}$ & $0.41^{\mathrm{a}}$ & $0.25^{\mathrm{a}}$ \\
\hline Gestation length (days) & $146.3 \pm 2.1^{\mathrm{a}}$ & $152.3 \pm 1.9^{\mathrm{a}}$ & $147 \pm 1.5^{\mathrm{a}}$ & $149.0 \pm 2.1^{\mathrm{a}}$ \\
\hline
\end{tabular}

Values within different superscripts in the same raw differ significantly $(\mathrm{P}<0.05)$.

$\mathrm{A}=$ contrpl group.

$\mathrm{B}=\mathrm{FGA}$ sponges.

$\mathrm{C}=\mathrm{FGA}+\mathrm{PMSG}$.

$\mathrm{D}=\mathrm{FGA}+\mathrm{PGF} 2 \alpha$.

\section{DISCUSSION}

The three synchronization methods employed in this study resulted in oestrus response in $65-80 \%$ of the treated goats. The responses in all hormonal protocols were as good as those of previous works (Muna et al., 1998; Chao et al., 2008; Abu et al., 2008). On the other hand, the oestrus response obtained in this study was lower than the $100 \%$ reported by Dogan et al. (2005). Oestrus response in the present study was not affected by synchronization methods; although 
lower response $(65 \%)$ was recorded on PGF2 $\alpha$ treatment. Although PGF2 $\alpha$ seems to be very effective for rapid lysis of corpora lutea and subsequent falling of progesterone (Whitley and Jackson, 2004; Bitaraf et al., 2007), not all stages of the oestrus cycle are similarly receptive to PGF2 $\alpha$ treatment (Wildeus, 2000). Some goats in the flock will be in early stages of the luteal phase at the time of synchronization (Karikari et al., 2009). In the present trial, the progesterone effect (Treatment B) on oestrus synchronization in Nubian goats agrees with the earlier reports of Lassala et al. (2004) in crossbred Alpine x Boer and Abu et al. (2008) in West African Dwarf goats. Oestrus response and fertility vary greatly when intravaginal sponges are applied, dependent on species, breed, co-treatment, management and mating system (Wildeus, 2000).

The overall post-treatment conception rate with fresh diluted semen found in this study was 38.3.0\%. This finding is similar to the results of other works (Muna et al., 1998; Dogan and Nur 2006). The results are lower than that reported by Lassala et al. (2004); Dogan et al. (2005); Imasuen and Ikhimioya (2009) and Karikari et al. (2009). FGA treatments in this study with or without eCG yielded fertility rates (40 $45 \%)$ that were higher $(\mathrm{P}<0.05)$ than those in FGA/ PGF2 $\alpha$ treatment $(30 \%)$ and the control group $(20 \%)$ which indicated better response to hormonal treatments and AI compared to the control group which was hand mated. Hormonal treatments can stimulate follicular growth and affect the time of ovulation (Dogan et al., 2005). The use of FGA sponges in combination with eCG at withdrawal was successful for synchronization during the breeding season in sheep and goats (Fonseca et al., 2005; Dogan and Nur 2006; Mehmet and Mehmet, 2006). The use of eCG resulted in a more predictable occurrence of oestrus. One limitation of eCG after long-term use is the active production of anti eCG antibodies which decreases fertility in goats (Leboeuf et al., 1998; Fonseca et al., 2005).

In the present study, AI in synchronized does was carried out at a fixed time following sponge withdrawal. The low conception rate recorded could be attributed to the inseminations being executed too late in some goats in the flock or in early stages of the luteal phase at the time of synchronization (Chao et al., 2008; Karikari et al., 2009). A decrease in fertility following progestin-based synchronization of oestrus in the absence of a corpus luteum has been observed (Lassala et al., 2004). It means that when applying artificial insemination in fixed time in induced oestrus in goats, interval to oestrus should be considered (Fonseca et al., 2005). 
In the present study, kidding rate, fecundity, twining rate and gestation length were not significantly affected by synchronization methods. Similarly, reproductive performance of Sudanese Nubian goats (Muna et al., 1998) and Nadooshani goats (Bitaraf et al., 2007) was not significantly affected. The results in this study showed low kidding rate. High incidence of embryonic loss was also reported by Muna et al. (1998). It was suggested that the high loss of embryos after synchronization and insemination was caused by functional poor corpora lutea bringing low doses of progesterone (Chao et al., 2008). Although fecundity was not significantly different between hormonal treatments, it increased $(\mathrm{P}<0.05)$ over that of the control and it was better in eCG groups, suggesting that treatment with eCG after the removal of the sponge influenced the fertility or fecundity rates (Mehmet and Mehmet, 2006). The gestation length (146 - 152 days) was not significantly different between groups and within the normal range (144 - 155 days) reported by Bitaraf et al. (2007). Twining rate in the present study was not significantly different between treatment groups. The results showed better reproductive performance with treatments $\mathrm{B}$ and $\mathrm{C}$.

In conclusion, it can be said that progesterone treatments (FGA) intravaginal sponges and their combinations with either eCG or PGF2 $\alpha$ in Nubian goats are efficient in synchronizing oestrus. FGA with or without eCG seems to be more convenient.

\section{REFERENCES}

Abu, A.H.; Iheukwumere, F.C. and Onyekwere, M.U. (2008): Effect of exogenous progesterone on oestrus response of West African Dwarf (WAD) goats. Afri. J. Biotech. 7 (1): 59-62.

Bitaraf, A.; Zamiri, M.J.; Kafi, M. and Izadifrad, J. (2007): Efficacy of CIDR, fluogestone acetate sponges and cloprostenol for oestrus synchronization of Nadooshani goats during the breeding season. Iranian J. Vet. Res. 8(3): 218-224.

Chao, Lu Meng; Takayama, K.; Nakanishi, Y.; Hamana, K.; Takagi, M.; Kubota, C. and Kojima, T. (2008): Luteal lifespan and fertility after oestrus synchronization in goats. J. Vet. Sci. 9(1): 95-101.

Dogan, I. and Nur, Z. (2006): Different oestrous induction methods during the non-breeding season in Kivircik ewes. Vet. Med. 51(4): 133-138.

Dogan, I.; Nur, Z.; Gunay, U.; Soylu, M.K. and Sonmez, C. (2005): Comparison of fluorgestone and medroxyprogesterone 
intravaginal sponges for oestrus synchronization in Saanen does during the transition period. South Afri. J. Anim. Sci. 34 (1): $18-22$.

Faruk, M.I.; Fatema, B.Z.; Bari, F.Y. and Alam, M.G.S. (2004): Effects of Alfaprostol and Luprostiol on the oestrus synchronization responses in Black Bengal goats. Bengl. J. Vet. Med. 2(2): 143-145.

Fonseca, J.F.; Bruschi, J.H.; Zambrini, F.N.; Demczuk, E.; Viana, J.H.M. and Palhão, M.P. (2005): Induction of synchronized oestrus in dairy goats with different gonadotrophins. Anim. Reprod. 2 (1): 50-53.

Imasuen, J.A. and Ikhimioya, I. (2009): An assessment of the reproductive performance of oestrus synchronized West African Dwarf (WAD) does using medroxyl-progesterone acetate (MPA). Afri. J. Biotech. 8(1): 103-106.

Karikari, P.K.; Blasu, E.Y. and Osafo, E.L.K. (2009): Reproductive response of West African Dwarf Does to prostaglandin administration. World Appl. Sci. J. 6(4): 542-545.

Lassala, A.; Hernandez-Ceron, J.; Rodriguez-Maltos, R. and Gutierrez, C.G. (2004): The influence of the corpus luteum on ovarian follicular dynamics during oestrus synchronization in goats. Anim. Reprod. Sci. 84: 369-375.

Leboeuf, B.; Manfredi, E.; Bout, P.; Piacere, A.; Brice, G.; Baril, G.; Broqua, C.; Hublot, P. and Terqui, M. (1998): Artificial insemination of dairy goats in France. Livestock Prod. Sci. 55: 193-203.

Mehmet, B.A. and Mehmet, A. (2006): GNRH-PGF2 $\alpha$ and PGF2 $\alpha$ synchronization in Akkaraman cross-bred sheep in the breeding season. Bull. Vet. Inst. Pulawy 50: 101-104.

Muna, M.M.; Makawi, S.E. and Jubara, A.S. (1998): Synchronization of oestrus in Nubian goats. Small Rum. Res. 30: 113-120.

Whitley, N.C. and Jackson, D.J. (2004): An update on oestrus synchronization in goats: A minor species. J. Anim. Sci. 82(Suppl.): 270-276

Wildeus, S. (2000): Current concepts in synchronization of oestrus: Sheep and goats. Proceedings of the American Society of Animal Science. Pp 1-14. 